\title{
AGE-RELATED MACULAR DEGENERATION - CURRENT STATE OF THE PROBLEM AND PROPHYLAXIS METHODS
}

DOI: 10.36740/WLek202103238

\author{
Tetiana M. Komarova, Oksana P. Vitovska, Julia I. Komisarenko, Vita M. Kohan \\ BOGOMOLETS NATIONAL MEDICAL UNIVERSITY, KYIV, UKRAINE
}

\begin{abstract}
The aim: Analyze the ophthalmic studies on diagnostics and treatment of patients with age-related macular degeneration to optimize diagnostics and management tactics. Materials and methods: The analysis of scientific papers due to age-related macular degeneration, vitamin D and its functions from scientometric databases: PubMed, Scopus, Web of Science. The methods were next: systematic approach, analysis, summarization and comparison.

Conclusions: Age-related macular degeneration is a chronic, progressive disease among people older than 50 years. Late diagnostics and inappropriate treatment may lead to irreversible central vision loss and social disadaptation. Modern studies on the pathogenesis and treatment of this pathology (that are due to the role of the immune system, antioxidants and microelements) demonstrate the effectiveness and prospects for further development around the world to find new ways to solve this problem.
\end{abstract}

KEY WORDS: age-related macular degeneration, vitamin D, vitamin D receptor, oxidative stress, immune response

Wiad Lek. 2021;74(3 p.II):767-772

\section{INTRODUCTION}

Nowadays irreversible vision loss is one of the global problems. This is not only a medical problem, but also a socio-economic one. Age-related macular degeneration (AMD) is third in the world (causes about $6,6 \%$ of cases of blindness) after cataract and glaucoma, and each year this amount continues to grow, adding 600,000 new cases [1 - 4]. This can be characterized by the fact that in the developed world the average life expectancy is increasing, the nation is aging, the incidence of chronic diseases is growing, and the population has more opportunities for adequate diagnosis of eye diseases.

Wong and colleagues, analyzing the main trends in the incidence of AMD, has estimated that by 2020 around 196 million people will suffer from this disease in the world, and by 2040 this figure will almost double to 288 million people $[5,6]$. European research shows that by 2050,77 million people in Europe will suffer from AMD. The incidence of new cases will increase by $75 \%$ [7].

A prospective multicenter randomized clinical trial of age-related macular degeneration (AREDS - Age-Related Eye Disease Study) [8] has found that more than $10 \%$ of the population aged 65-74 had symptoms and signs of AMD, whereas in population older than 75 years this figure has increased significantly and was $25 \%$, while among people older than 85 years - was more than $30 \%$. It has been reported that in the presence of symptoms and signs of AMD in one eye, the other eye is affected in 5 years [9]. AMD does not cause complete blindness among people older than 50 years, this disease significantly affects their perception of the outside world: every day it becomes harder to go shopping, to recognize the faces of beloved ones, people are gradually losing the ability to self-care. Rapid loss of vision occurs when AMD becomes exudative. Measures that slow down the AMD transition from dry to exudative form by the correction of pathogenetic changes, thus, are relevant. This, in turn, is the social significance of this issue around the world.

\section{THE AIM}

Analyze the ophthalmic studies on diagnostics and treatment of patients with age-related macular degeneration to optimize diagnostics and management tactics.

\section{MATERIALS AND METHODS}

The analysis of scientific papers due to age-related macular degeneration, vitamin $\mathrm{D}$ and its functions from scientometric databases: PubMed, Scopus, Web of Science. The methods were next: systematic approach, analysis, summarization and comparison.

\section{REVIEW AND DISCUSSION}

Age-related macular degeneration (AMD) is a multifactorial disease: metabolic and genetic factors play a role in its pathogenesis. One of the main causes of AMD today is considered to be oxidative stress and inflammation, which cause irreversible progressive loss of retinal photoreceptors $[10,11]$. As one of the most highly differentiated nerve tissues in the human body, the retina is extremely sensitive 
to hypoxia and ischemia [10]. As a result of numerous biochemical reactions, a significant amount of free radicals is formed, which have a detrimental effect on retinal cells.

There are the following processes in the pathogenesis of AMD [12 -16]:

1) primary aging of the retinal pigment epithelium (RPE) and Bruch's membrane - macular pigment - is the only antioxidant in the retina that actively neutralizes the action of free radicals and passively retains or absorbs blue light, which causes photooxidative damage;

2) damage of the retina by the products of lipid peroxidation - activation of free radical oxidation causes the damage of proteins, nucleic acids, especially lipids of cell membranes, which are very easily involved in the free radical reaction chain. Disturbance of the balance between oxidative and antioxidant systems affects the integrity of the complex of photoreceptors and RPE, leads to the accumulation of cell breakdown products, lipofuscin granules and the formation of drusen;

3) primary genetic defects - inherited nature of AMD with autonomous-dominant type of inheritance. It was found that people who are relatives in the first generation are 3 times more likely to get $\mathrm{AMD}$, provided that one person has already shown signs of AMD;

4) pathological changes in the blood supply of the eyeball - impaired microcirculation in the choriocapillaris - the only source of blood supply of the macular area - due to the background of age-related changes in the RPE and Bruch's membrane may be the beginning of the dystrophic process. In the presence of atherosclerosis, the risk of developing AMD increases 3 times (localization of plaque in the common carotid artery - 2,5 times, in the bifurcation of the carotid arteries - 4,7 times).

According to the classification, AMD is divided into dry (non-exudative) and wet (exudative) form, with a predominance of dry (about 90\%) in the incidence of the population $[8,17]$. The AREDS classification, proposed by the American Academy of Ophthalmology, is the most often used one in the world. According to this classification, dry AMD includes the following stages:

category 1 - absence of AMD - absence or insignificant number of small drusen (up to 63 microns in diameter according to optical coherence tomography);

category 2 - early stage of AMD - a significant number of small drusen, a small number of medium size drusen (diameter 64-124 microns) or changes in the RPE;

category 3 - intermediate stage of AMD - a significant number of medium size drusen, at least one large drusen (diameter more than 125 microns) or geographical atrophy of the retina, which does not affect the central fovea;

category 4 - late stage of AMD - geographical atrophy of the retina, which affects the central fovea.

The wet form of AMD involves exudative detachment of the retinal RPE and retinal neuroepithelium, choroidal neovascularization and the formation of fibrovascular scar in the central fovea of the retina.

Nowadays, scientists around the world recommend the use of antioxidant drugs in treatment of dry AMD. One of the good combinations is a special formula AREDS2, which includes: $500 \mathrm{mg}$ of vitamin C, $400 \mathrm{ME}$ of vitamin $\mathrm{E}, 10 \mathrm{mg}$ of lutein, $2 \mathrm{mg}$ of zeaxanthin, $80 \mathrm{mg}$ of zinc in the form zinc oxide, $2 \mathrm{mg}$ of copper in the form of copper oxide [18 - 20]. Intravitreal injections of anti-VEGF factor inhibitors (aflibercept, bevacizumab, ranibizumab) are used to treat the wet form of AMD $[9,17]$. However, these injections have a limited duration of action on patients and require frequent use (every few months), which to some extent limits patients and their relatives.

In recent years, many studies have been conducted on the role of vitamin $\mathrm{D}$ in chronic eye diseases, including AMD [21 - 25]. Performing the functions of both vitamin and hormone in the human body, its active metabolites are involved in the regulation of calcium-phosphorus metabolism, cell proliferation and have an immunomodulatory effect. Its receptors (vitamin D receptor - VDR) are found in many organs, including the retina and immune system cells $[26-28,31,32]$.

Vitamin D is not a biologically active vitamin; its clinical effects are manifested after interaction with specific receptors located in cell nuclei, after activation in liver and kidneys $[29,30]$. These conditions give the second name to vitamin $\mathrm{D}-\mathrm{D}$-hormone. Vitamin $\mathrm{D}$ is a combination of several different compounds (seco-steroids), but only $\mathrm{D}_{2}$ and $\mathrm{D}_{3}$ types are biologically important:

$\mathrm{D}_{1}$ - ergocalciferol in combination with lumisterol;

$\mathrm{D}_{2}$ - ergocalciferol, enters the body with plant products (bread, etc.). It is synthesized from ergosterol - sterol secreted by yeast fungi. It is produced under the influence of ultraviolet light;

$\mathrm{D}_{3}$ - cholecalciferol, $80 \%$ of vitamin $\mathrm{D}_{3}$ is formed in the skin from dehydrocholesterol under the action of ultraviolet light. $20 \%$ of it enters the body with food of animal origin (fish oil, liver, egg yolk);

$\mathrm{D}_{4}$ - dehydrocholesterol, is found in the body and skin of animals and humans. Due to the action of ultraviolet light on human skin it synthesizes vitamin $\mathrm{D}_{3}$;

$\mathrm{D}_{5}$ - sitocalciferol, is extracted from wheat grains by chemical synthesis; is a nutrient component of wheat germ.

$\mathrm{D}_{6}$ - sigma-calciferol, is found in plant foods, has little value, but may be an alternative for people who are vegetarians.

Absorption of ergocalciferol $\left(D_{2}\right)$ from food occurs in the duodenum with the participation of bile acids $[33,34]$.

Cholecalciferol $\left(\mathrm{D}_{3}\right)$ is formed from the precursor of 7-dehydrocholesterol (located in the malpighian layer of the skin) under the action of ultraviolet light $[29,30]$.

Once in the human body, vitamin D is incorporated into the structure of chylomicrons, circulates in the blood and binds to vitamin $\mathrm{D}$-binding protein, from which it is separated in the liver $[33,34]$.

Then in the liver (especially in hepatocytes) 25-OH-hydroxycholecalciferol (calcidol) is formed from both forms of vitamin $\mathrm{D}$ as a result of hydroxylation (addition of the OH group) $[29,30]$. This form is both a depot and a transport, and it is determined in the blood to estimate the level of vitamin $\mathrm{D}$. The hydroxylation reaction is a substrate-de- 
pendent process, proceeds rapidly and causes an increase in serum $25-\mathrm{OH}-\mathrm{D}_{3}$. $[29,30]$ The half-life time of $25-\mathrm{OH}-\mathrm{D}_{3}$ in blood is up to 30 days, which can be explained by the relatively high affinity of $25(\mathrm{OH}) \mathrm{D}_{3}$ to vitamin $\mathrm{D}$-binding protein $[29,30]$. Some amount of vitamin $\mathrm{D}$ is deposited in adipose and muscle tissue.

After this the second stage of hydroxylation is done in the kidneys with the help of parathyroid hormone (hormone of the parathyroid glands). It includes the interaction with <1-hydroxylase enzyme (localized in the mitochondria of the proximal convoluted tubules of the kidneys). And there is the formation of the active form - 1,25( $\mathrm{OH})$-dihydroxycholecalciferol. From $0,3 \mu \mathrm{g}$ to $1,0 \mu \mathrm{g}$ of calcitriol is formed per day $[29,30]$. It is calcitriol that provides the main biological effects of vitamin $\mathrm{D}$ in the body: increasing the serum calcium concentration by increasing its absorption from the intestine and reabsorption in the kidneys [29, 30, 33]. The half-life time of $1,25(\mathrm{OH})_{2} \mathrm{D}_{3}$ in the blood is 4 hours. When the concentration of calcium and phosphorus in the blood reaches normal values, the activity of 24-hydroxylase enzyme increases and 24,25-dihydroxycholecalciferol is formed. It fixes calcium and phosphorus in the bone tissue $[29,30]$. Parathyroid hormone is regulated by a feedback mechanism - an increase in the concentration of calcitriol in the blood causes a decrease in its secretion $[29,30,35]$. Also, the processes of $\langle 1$-hydroxylation are influenced by sex hormones (androgens, estrogen), prolactin, calcitonin and others $[29,30]$.

Most of the metabolites of vitamin D in the blood are associated with albumin (10-20\%) or vitamin D-binding protein $(80-90 \%)$. The complex of vitamin D and transport protein is able to bind with specific receptors and enter the cell, where vitamin D exhibits active properties. Only a small fraction $(0,02-0,05 \%$ of 25 -hydroxyvitamin $\mathrm{D}$ and $0,2-0,6 \%$ of 1,25 -dihydroxyvitamin D) of vitamin D metabolites is present in the blood in the free state $[29,30]$. The concentration of non-protein metabolites of vitamin $\mathrm{D}$ is maintained at a fairly stable level even in liver disease and reduced production of vitamin D-binding protein and therefore is not a good indicator of the dynamics of vitamin D status of the body $[29,36]$.

Because vitamin D is a fat-soluble vitamin, it is able to accumulate in the human body in various organs. The largest amount is contained in the subcutaneous fat and liver [29]. Thus, there is always some depot of vitamin D, from which this compound is consumed in case of insufficient food intake.

Vitamin D production is inhibited by indoor glass, clouds, air pollution, clothing and sunscreen. The use of sunscreen with a factor of 15 (SPF 15) reduces the synthesis of vitamin D in the skin by $99 \%$ [37].

Sufficient amount of fat and bile are needed to absorb the vitamin into the blood from the intestines $[29,33,34]$. Therefore, for better absorption of vitamin D, it should be taken with vegetable fats. With sufficient amount of fat and bile, vitamin D is absorbed up to $90 \%$, but in their absence - only up to $60 \%$. The absorption of synthetic vitamins $\mathrm{D}$ does not depend on the amount of fat and bile, so pharmacological drugs may be more effective than natural compounds $[29,30,33,34]$.

One of the functions of vitamin D is an anti-inflammatory effect $[21,26,27]$.

VDRs to $1,25(\mathrm{OH})_{2} \mathrm{D}_{3}$ have been identified in more than 38 tissues, where vitamin D clearly controls vital genes associated with bone metabolism, oxidative damage, chronic disease and inflammation [21,26,27].

VDR is expressed by macrophages and dendritic cells, suggesting that vitamin $\mathrm{D}$ plays an important role in modulating the inflammatory response $[26,27,39] .1,25(\mathrm{OH})_{2} \mathrm{D}_{3}$ can be synthesized by both cell types because they express the enzymes 25-hydroxylase and a1-hydroxylase, which allow to produce $25(\mathrm{OH}) \mathrm{D}_{3}$ and $1,25(\mathrm{OH})_{2} \mathrm{D}_{3}$, respectively $[39,41,42]$. In macrophages and dendritic cells, the enzyme a1-hydroxylase is predominantly regulated by inflammatory mediators such as interferon- $\gamma($ IFN- $\gamma)$ and lipopolysaccharides [39, 43].

Macrophages are cells with a high capacity to produce cytokines, in particular TNF- $\alpha$, which is one of the most important products secreted by these cells $[39,44]$. Transcriptional activation of the TNF- $\alpha$ gene in macrophages largely depends on the activation of NF- $\kappa \mathrm{B}$ transcription, which is the main regulator of immune, inflammatory and stress responses $[39,45]$. In lipopolysaccharide- stimulated mouse macrophages, $1,25(\mathrm{OH})_{2} \mathrm{D}_{3}$ regulates the NF- $\kappa \mathrm{B}$ (I $\mathrm{B}-\alpha$ ) inhibitor by increasing mRNA stability and reducing IkB- $\alpha$ phosphorylation. An increase in the level of I $\kappa \mathrm{B}-\alpha$ leads to a decrease in the nuclear translocation of $\mathrm{NF}-\kappa \mathrm{B}$, thereby causing a decrease in activity. Given the key role of NF- $\mathrm{KB}$ as a transcription factor for inflammatory mediators, it should be assumed that $1,25(\mathrm{OH})_{2} \mathrm{D}_{3}$ has anti-inflammatory effects in macrophages $[39,46]$. In addition, $1,25(\mathrm{OH})_{2} \mathrm{D}_{3}$ inhibits the expression of TLR2 and TLR4 protein and mRNA in human monocytes. [39, 47]. Incubation of isolated monocytes with $1,25(\mathrm{OH})_{2} \mathrm{D}_{3}$ attenuates the expression of proinflammatory cytokines such as IL-1, IL-6 and TNF- $\alpha[39,48,49,50]$.

Some studies show that hypovitaminosis of vitamin $\mathrm{D}$ is associated with higher levels of serum inflammatory biomarkers, such as IL-6, TNF- $\alpha$ and C-reactive protein (CRP), in healthy $[39,51-54]$ and obese people.

Studies have shown the presence of VDR in immune system cells and a1-hydroxylase in macrophages and dendritic cells. The data obtained indicate the local production of 1,25( $\mathrm{OH})$-dihydroxycholecalciferol, which has auto- and paracrine properties at the site of inflammation $[26,27,55]$. Next, $1,25(\mathrm{OH})_{2} \mathrm{D}_{3}$ binds to VDR and modulates tissue gene expression in a specific way. Some cells, including cells of the immune system, have a1-hydroxylase and VDR and can synthesize the hormonal form of vitamin $\mathrm{D}$ from circulating in the blood $25(\mathrm{OH}) \mathrm{D}_{3}$, and therefore extrarenal a1-hydroxylase acts differently in response to parathyroid hormone, calcium and phosphorus compared with renal a1-hydroxylase. Thus, extrarenal a1-hydroxylase is not regulated by parathyroid hormone, the secretion of $1,25(\mathrm{OH})_{2} \mathrm{D}_{3}$ depends on the substrate concentration of $25(\mathrm{OH}) \mathrm{D}_{3}$. The process is substrate-dependent and 
requires a sufficient level of saturation of the body with vitamin $\mathrm{D}[26,27,55]$.

In a number of studies, scientists have observed that cells from foci of inflammation (compared to healthy cells of the same organism) have an increase in the concentration of active metabolites of vitamin $\mathrm{D}$, which may indicate its anti-inflammatory effect $[26,27,56]$. Active metabolites of vitamin $D$ with the help of cytokines inhibit the occurrence of severe inflammation in various organs and tissues of the body, where there are receptors for vitamin $\mathrm{D}$, including eye tissues. Nuclear receptors for calcitriol are found in cells of the central and peripheral nervous system (neurons of the brain, glial cells, spinal cord) $[26,56,57]$.

The daily requirement of vitamin $\mathrm{D}$ is $400 \mathrm{IU}$ for children and $200 \mathrm{IU}$ for adults, sufficient supply of vitamin D is in the range of 40-100 $\mathrm{ng} / \mathrm{ml}$. Decreased levels of vitamin D in the blood cause a state of its deficiency and insufficiency, thus disrupting metabolic processes in the body $[29,30]$.

The action of vitamin $\mathrm{D}$ is of interest to scientists around the world. There are many studies that observe the effects of vitamin D metabolites on AMD. However, data from various studies have led to controversial conclusions, not giving the opportunity to unambiguously answer questions about the benefits of adding vitamin $\mathrm{D}$ drugs to stabilize the process.

\section{CONCLUSIONS}

Age-related macular degeneration is a chronic, progressive disease among people older than 50 years. Late diagnostics and inappropriate treatment may lead to irreversible central vision loss and social disadaptation. Modern studies on the pathogenesis and treatment of this pathology (that are due to the role of the immune system, antioxidants and microelements) demonstrate the effectiveness and prospects for further development around the world to find new ways to solve this problem.

\section{REFERENCES}

1. Prenner J.L., Halperin L.S., Rycroft C., et al. Disease Burden in the Treatment of Age-Related Macular Degeneration: Findings From a Time-and-Motion Study. American Journal of Ophthalmology. 2015;160(4):725-731.

2. World Health Organization: Prevention of blindness and visual impairment. Priority eye diseases-corneal opacities. 2010. http://www. who.int/blindness/causes/priority/en/index9. html.

3. Vitovskaya 0. Stategy of health promotion in ophthalmology. RMJ Klinicheskaya ophthalmologiya. 2013;3: 88-91. (in Russian).

4. Pasechnikova N.V., Rukov S.0., Vitovska 0.P.et al. Analis stany ophthalmologichnoi dopomogu naselenniy Ukrainu y 2006-2011 rokah. Ophthalmological journal. 2012;6: 131-140. (in Ukrainian).

5. Wong T.Y., Chakravarthy U., Klein R. et al. The natural history and prognosis of neovascular age-related macular degeneration: a systematic review of the literature and meta-analysis. Ophthalmology. 2008; 115: 116-26.

6. Wong W.L., Su X., Li X. et al. Global prevalence of age-related macular degeneration and disease burden projection for 2020 and 2040: a systematic review and meta-analysis. Lancet Glob Health. 2014. http:// dx.doi.org/10.1016/S2214-109X(13)70145-1.
7. Age related macular degeneration to affect 77 million Europeans by 2050. British Medical Journal. 11 November 2019. https://medicalxpress.com/ news/2019-11-age-macular-degeneration-affect-million.html

8. Age-Related Eye Disease Study Research Group. The Age-Related Eye Disease Study (AREDS): design implications. AREDS report no. 1. Controlled clinical trials. 1999; 20(6): 573-600. https://doi. org/10.1016/s0197-2456(99)00031-8

9. Age-related macular degeneration NICE guideline. 2018. www.nice. org.uk/guidance/ng82.

10. Anderson D.H., Radeke M.J., Gallo N.B. et al. The pivotal role of the complement system in aging and age-related macular degeneration: hypothesis re-visited. Prog Retin Eye Res. 2010;29:95-112.

11. Chakravarthy U., Wong T., Fletcher A. et al. Clinical risk factors for agerelated macular degeneration: a systematic re-view and meta-analysis. BMC Ophthalmology. 2010;10:31.

12. Bellezza I. Oxidative Stress in Age-Related Macular Degeneration: Nrf2 as Therapeutic Target. Frontiers in pharmacology. 2018; 9: 1280. https:// doi.org/10.3389/fphar.2018.01280.

13. Tuo J., Bojanowski C. M., Chan C.C. Genetic factors of age-related macular degeneration. Progress in retinal and eye research. 2004;23(2):229-249. https://doi.org/10.1016/j.preteyeres.2004.02.001.

14. Lipecz A., Miller L., Kovacs I. et al. Microvascular contributions to age-related macular degeneration (AMD): from mechanisms of choriocapillaris aging to novel interventions. GeroScience. 2019;41(6): 813-845. https://doi.org/10.1007/s11357-019-00138-3.

15. Farazdaghi M.K., Ebrahimi K.B. Role of the Choroid in Age-related Macular Degeneration: A Current Review. Journal of ophthalmic \& vision research. 2019;14(1): 78-87. https://doi.org/10.4103/jovr.jovr_125_18.

16. Heesterbeek T. J., Lorés-Motta L., Hoyng C.B. et al. Risk factors for progression of age-related macular degeneration.. Ophthalmic Physiol Opt. 2020; 40(2): 140-170. doi: 10.1111/opo.12675. PMCID: PMC7155063.

17. Flaxe C.J., Adelman R. A., Bailey S. T. et al.Age-Related Macular Degeneration Preferred Practice Pattern. Ophthalmology 2020; 127(1):1-65. D0l: 10.1016/j.ophtha.2019.09.024.

18. Chew E. Y., Clemons T., SanGiovanni J. P. et al. AREDS2 Research Group. The Age-Related Eye Disease Study 2 (AREDS2): study design and baseline characteristics (AREDS2 report number 1). Ophthalmology. 2012;119(11):2282-2289. https://doi.org/10.1016/j. ophtha.2012.05.027.

19. Age-Related Eye Disease Study 2 Research Group. Lutein + zeaxanthin and omega-3 fatty acids for age-related macular degeneration: the AgeRelated Eye Disease Study 2 (AREDS2) randomized clinical trial. JAMA. 2013;309(19): 2005-2015. https://doi.org/10.1001/jama.2013.4997.

20. Keenan T. D., Agrón E., Domalpally A. et al. Progression of Geographic Atrophy in Age-related Macular Degeneration: AREDS2 Report Number 16. Ophthalmology. 2018; 125(12): 1913-1928. https://doi. org/10.1016/j.ophtha.2018.05.028.

21. Skowron K., Pawlicka I., Gil K. The role of vitamin D in the pathogenesis of ocular diseases. Folia medica Cracoviensia. 2018;58(2): 103-118. https://doi.org/10.24425/fmc.2018.124662.

22. Wu S., Sun J. Vitamin D, vitamin D receptor, and macroautophagy in inflammation and infection. Discovery medicine. 2011;11(59): 325-335.

23. Merle B., Silver R. E., Rosner B., Seddon J. M. Associations Between Vitamin D Intake and Progression to Incident Advanced Age-Related Macular Degeneration.Investigative ophthalmology \& visual science. 2017;58(11): 4569-4578. https://doi.org/10.1167/iovs.17-21673. 
24. Kaarniranta K., Pawlowska E., Szczepanska J. et al. Can vitamin D protect against age-related macular degeneration or slow its progression?. Acta biochimica Polonica. 2019;66(2): 147-158. https://doi.org/10.18388/ abp.2018_2810.

25. Golan S., Shalev V., Treister G. et al. Reconsidering the connection between vitamin $D$ levels and age-related macular degeneration. Eye (London, England). 2011;25(9):1122-1129.https://doi.org/10.1038/eye.2011.174.

26. Bivona G., Agnello L., Ciaccio M. The immunological implication of the new vitamin D metabolism. Central-European journal of immunology. 2018; 43(3):331-334. https://doi.org/10.5114/ceji.2018.80053.

27. Ambati J., Atkinson J. P., Gelfand B. D. Immunology of age-related macular degeneration. Nature reviews. Immunology. 2013;13(6): 438-451. https://doi.org/10.1038/nri3459.

28. Millen A. E., Voland R., Sondel S. A. et al. Vitamin D status and early age-related macular degeneration in postmenopausal women. Archives of ophthalmology (Chicago, Ill. : 1960). 2011; 129(4): 481-489. https:// doi.org/10.1001/archophthalmol.2011.48.

29. HolickM.F.Vitamin D requirements for humans of all ages: new increased requirements for women and men 50 years and older. 0steoporos Int. 1998;8(2):24-9. doi: 10.1007/pl00022729.

30. Hilger J., Friedel A., Herr R. et al. A systematic review of vitamin D status in populations worldwide. The British journal of nutrition. 2014; 111(1): 23-45. https://doi.org/10.1017/S0007114513001840.

31. Mousa A., Misso M., Teede H. et al. Effect of vitamin D supplementation on inflammation: protocol for a systematic review. BMJ. 2016;6(4): e010804. https://doi.org/10.1136/bmjopen-2015-010804.

32. Morrison M. A., Silveira A. C., Huynh N. et al. Systems biology-based analysis implicates a novel role for vitamin D metabolism in the pathogenesis of age-related macular degeneration. Human genomics. 2011;5(6): 538-568. https://doi.org/10.1186/1479-7364-5-6-538.

33. Maurya V. K., Aggarwal M. Factors influencing the absorption of vitamin D in GIT: an overview. Journal of food science and technology. 2017; 54(12): 3753-3765. https://doi.org/10.1007/s13197-017-2840-0.

34. Ross A.C., Taylor C.L., Yaktine A.L. et al. Institute of Medicine (US) Committee to Review Dietary Reference Intakes for Vitamin $D$ and Calcium;. Dietary Reference Intakes for Calcium and Vitamin D. Washington (DC): National Academies Press (US). 2011:3.

35. Carrillo-López N., Fernández-Martín J. L., Cannata-Andía J. B. Papel de calcio, calcitriol y sus receptores en la regulación de la paratiroides [The role of calcium, calcitriol and their receptors in parathyroid regulation].Nefrologia :publicacion oficial dela Sociedad Espanola Nefrologia 2009;29(2): 103-108. https://doi.org/10.3265/Nefrologia.2009.29.2.5154.en.full.

36. Yousefzadeh P., Shapses S. A., Wang X. Vitamin D Binding Protein Impact on 25-Hydroxyvitamin D Levels under Different Physiologic and Pathologic Conditions. International journal of endocrinology. 2014;981581. https://doi.org/10.1155/2014/981581.

37. Passeron T., Bouillon R., Callender V. et al. Sunscreen photoprotection and vitamin D status. The British journal of dermatology. 2019; 181(5): 916-931. https://doi.org/10.1111/bjd.17992.

38. Bishop E., Ismailova A., Dimeloe S. K. et al. Vitamin $D$ and immune regulation: antibacterial, antiviral, anti-inflammatory. JBMR. 2020. https://doi.org/10.1002/jbm4.10405.

39. Dadrass A., Mohamadzadeh Salamat K., Hamidi K., Azizbeigi, K. Anti-inflammatory effects of vitamin $D$ and resistance training in men with type 2 diabetes mellitus and vitamin $D$ deficiency: a randomized, double-blinded, placebo-controlled clinical trial. Journal of diabetes and metabolic disorders. 2019; 18(2): 323-331. https://doi.org/10.1007/ s40200-019-00416-z.
40. Das G. Vitamin D and type 2 diabetes. Pract Diabetes. 2017;34(1):19-24. doi: 10.1002/pdi.2072.

41. Shab-Bidar S., Neyestani T.R., Djazayery A. et al. Improvement of vitamin $D$ status resulted in amelioration of biomarkers of systemic inflammation in the subjects with type 2 diabetes. Diabetes Metab Res Rev. 2012;28:424-430. doi: 10.1002/dmrr.2290.

42. Miller E.G., Sethi P., Nowson C.A. et al. Effects of progressive resistance training and weight loss versus weight loss alone on inflammatory and endothelial biomarkers in older adults with type 2 diabetes. Eur J Appl Physiol. 2017;117(8):1669-1678. doi: 10.1007/s00421-017-3657-2.

43. Calton E.K., Kevin N., Keane K.N. et al. The impact of vitamin D levels on inflammatory status: a systematic review of immune cell studies. PLOS One. 2015;10(11):e0141770. doi: 10.1371/journal.pone.0141770.

44. Haussler M.R., Haussler C.A., Bartik L. et al.Vitamin D receptor: molecular signaling and actions of nutritional ligands in disease prevention. Nutr Rev. 2008;66:98-112. doi: 10.1111/j.1753-4887.2008.00093.x.

45. Sigmundsdottir H., Pan J., Debes G.F. et al. DCs metabolize sunlightinduced vitamin D3 to "program" T cell attraction to the epidermal chemokine CCL27. Nat Immunol. 2007;8:285-293. doi: 10.1038/ni1433.

46. JablonskiK.L.,ChoncholM.,PierceG.L.etal.25-HydroxyvitaminDdeficiency is associated with inflammation-linked vascular endothelial dysfunction in middle-aged and older adults. Hypertension.2011;57:63-69. doi: 10.1161/HYPERTENSIONAHA.110.160929.

47. Zhang Z., Zhao M., Li Q. et al. Acetyl-I-carnitine inhibits TNF-alphainduced insulin resistance via AMPK pathway in rat skeletal muscle cells. FEBS Lett. 2009;583(2):470-474. doi: 10.1016/j.febslet.2008.12.053.

48. Nabata A., Kuroki M., Ueba H. et al. C-reactive protein induces endothelial cell apoptosis and matrix metalloproteinase- 9 production in human mononuclear cells: implications for the destabilization of atherosclerotic plaque. Atherosclerosis. 2008;196:129-135. doi: 10.1016/j.atherosclerosis.2007.03.003.

49. Salamat K.M., Azarbayjani M.A., Yusof A., Dehghan F. The response of pre-inflammatory cytokines factors to different exercises (endurance, resistance, concurrent) in overweight men. Alex J Med. 2016;52:367370. doi: 10.1016/j.ajme.2015.12.007.

50. Mora S., Lee I.M., Buring J.E., Ridker P.M. Association of physical activity and body mass index with novel and traditional cardiovascular biomarkers in women. JAMA. 2006;295(12):1412-1419. doi: 10.1001/ jama.295.12.1412.

51. Penninx B.W., Kritchevsky S.B., Newman A.B. et al. Inflammatory markers and incident mobility limitation in the elderly. J Am Geriatr Soc. 2004;52:1105-1113. doi: 10.1111/j.1532-5415.2004.52308.x.

52. Levinger I., Goodman C., Peake J. et al. Inflammation, hepatic enzymes and resistance training in individuals with metabolic risk factors. Diabet UK Diabet Med. 2009;26(6):220-227. doi: 10.1111/j.14645491.2009.02679.x.

53. Hopps E., Canino B., Caimi G. Effects of exercise on inflammation markers in type 2 diabetic subjects. Acta Diabetol. 2011;48(3):183-189. doi: 10.1007/s00592-011-0278-9.

54. Christiansen T., Paulsen S.K., Bruun J.M. et al. Exercise training versus diet-induced weight-loss on metabolic risk factors and inflammatory markers in obese subjects: a 12-weeks randomized intervention study. Am J Physiol Endocrinol Metab. 2010;298(4):E824-E831. doi: 10.1152/ ajpend0.00574.2009.

55. Lagishetty V., Chun R. F., Liu N. Q. et al. 1alpha-hydroxylase and innate immune responses to 25 -hydroxyvitamin $D$ in colonic cell lines. The Journal of steroid biochemistry and molecular biology. 2010; 121(1-2): 228-233. https://doi.org/10.1016/j.jsbmb.2010.02.004. 
56. Aranow C. Vitamin D and the immune system. Journal of investigative medicine : the official publication of the American Federation for Clinical Research. 2011; 59(6): 881-886. https://doi.org/10.2310/ JIM.0b013e31821b8755.

57. Bikle D. Vitamin D: Production, Metabolism, and Mechanisms of Action. [Updated 2017 Aug 11]. Endotext.South Dartmouth (MA): MDText.com, Inc. 2000. https://www.ncbi.nlm.nih.gov/books/NBK278935/

The article was performed in framework of research "Improving of diagnosis and treatment of retinal and optic nerve diseases of vascular, endocrine and traumatic origin", (20202022, № state registration 0120U100810).

\section{ORCID and contributionship:}

Tetiana M. Komarova: 0000-0002-7263-4067 B, C, D

Oksana P. Vitovska: 0000-0002-5786-5166 ${ }^{A, E, F}$

Julia I. Komisarenko: 0000-0001-9912-4879 A, E, F

Vita M. Konakh: 0000-0002-8760-0572 ${ }^{B, C}$

\section{Conflict of interest:}

The Authors declare no conflict of interest.

\section{CORRESPONDING AUTHOR}

Tetiana M. Komarova

Bogomolets National Medical University

13 T.Shevchenko boulevard, 01601 Kyiv, Ukraine

tel:+380660391453

e-mail: Bracos17@gmail.com

Received: 16.11 .2020

Accepted: 09.03.2021

A - Work concept and design, B - Data collection and analysis, C - Responsibility for statistical analysis,

$\mathbf{D}$-Writing the article, $\mathbf{E}$-Critical review, $\mathbf{F}$ - Final approval of the article 